\title{
Self-Efficacy, Internet Self-Efficacy, and Proxy
} Efficacy as Predictors of the Use of Digital Social
and Health Care Services Among Mental Health
Service Users in Finland: A Cross-Sectional Study

\author{
Birgitta Tetri $\mathbb{D}^{1,2}$, Soile Juujärvi $\mathbb{D}^{1}$ \\ 'Laurea University of Applied Sciences, Vantaa, Finland; ${ }^{2}$ Faculty of Social Sciences, University of Helsinki, Helsinki, Finland \\ Correspondence: Birgitta Tetri, Laurea University of Applied Sciences, Ratatie 22, Vantaa, 0I300, Finland, Email birgitta.tetri@Laurea.fi
}

\begin{abstract}
Background: The COVID-19 pandemic has accelerated the digitalization of services, but at the same time, some user groups are excluded due to a lack of digital skills. One of the vulnerable groups is people with mental health problems. It has previously been found that self-efficacy beliefs explain the use of digital technology, but the role of social support is largely unexamined. Bandura's concept of proxy agency provides a useful concept to investigate the role of social support in using digital services.

Objective: The study investigates sources of social support and the effect of proxy agency, Internet efficacy, and self-efficacy beliefs on the intention to use digital health and social care services.

Methods: Participants $(\mathrm{N}=121)$ were users in community-based mental health services who were recruited through four organizations in southern Finland for a cross-sectional study. The scales for proxy agency and intention to use services were developed for purpose of the study. The questionnaire also comprised self-efficacy and Internet efficacy scales. Quantitative data were analyzed using descriptive statistics and linear regression analysis.

Results: Both Internet self-efficacy and proxy efficacy $(p<0.001)$ predicted the intention to use digital health and social care services. Self-efficacy had an indirect positive effect on intention through Internet self-efficacy. Family members and friends were the main source of social support in using digital services.

Conclusion: Internet self-efficacy and proxy efficacy are important contributors to the intention to use digital health and social care services. Proxy agents may serve as facilitators to reduce the digital divide and promote the use of digital services by complementing individuals' self-efficacy and Internet self-efficacy beliefs. It is important to develop different forms of social support, such as peer support, to enhance the quality of proxy agency. The limitations of proxy agency are discussed.
\end{abstract}

Keywords: digital services, Internet self-efficacy, mental health service users, proxy efficacy, self-efficacy, social support

\section{Introduction}

\section{Background}

In the field of social and health care, new digital services are being offered to clients at a growing rate. These services allow and require clients to play a more active role in caring for their health and well-being. The COVID-19 pandemic has further increased the launch of digital services. The focus of care delivery has shifted towards digital alternatives over traditional face-to-face appointments whenever feasible. Rapid changes require adaptation from organizations, professionals, and customers alike. However, the proliferation of digital social and health care services may accelerate digital and social exclusion and increase inequality unless the most vulnerable groups are also able to access services. ${ }^{1,2}$

One vulnerable group is people with mental health difficulties who would benefit from digital services and who are also willing to use them. ${ }^{3,4}$ For example, a meta-analysis of 13 studies comparing Internet-delivered therapy and face-to-face therapy indicated that treating depression and anxiety disorders with online therapy was as effective as meeting in person. ${ }^{5}$ 
Both material deprivation and inadequate skills are contributing factors to digital exclusion, ${ }^{1,6,7}$ and rapid advances in digital technology increase the barriers to digital engagement even further. ${ }^{1}$ Affordability issues may prevent people with mental health difficulties from having access to the Internet. ${ }^{8,9}$ Furthermore, the opportunity to use the Internet itself does not necessarily secure access to web-based mental health resources. Users may be unaware of services provided in digital form ${ }^{10}$ or may experience difficulties due to outdated and incorrect information in the absence of reliable curation. ${ }^{11}$ Mental health problems themselves have an impact on digital exclusion when symptoms cause difficulties in using digital services and negatively affect one's feelings of competence and self-efficacy beliefs. ${ }^{7}$ In conclusion, mental health service users who might greatly benefit from web-based interventions are not able to access them. ${ }^{9}$

This study examines how self-efficacy, Internet self-efficacy, and proxy efficacy are associated with the intention to use digital social and health care services within a group of adult mental health service users. The reported sources of support to use digital services are also explored. The main theoretical starting points are related to the concepts of selfefficacy and proxy efficacy beliefs ${ }^{12,13}$ as well as the need and quality perspective of proxy agency. ${ }^{14,15}$ Groups with mental health problems benefit from and are willing to use digital social and health services. ${ }^{3}$ The prerequisite is to ensure that they have the basic skills needed to use them. It is essential to identify the lack of digital skills and the consequent risk of exclusion. Some studies have investigated the impact of different forms of efficacy beliefs and found that Internet self-efficacy and proxy efficacy promoted the use of services. ${ }^{16-18}$ However, the research on proxy efficacy beliefs related to digital social and health care services, especially in the mental health context, is lacking, and further knowledge is required to secure the availability of adequate and high-quality support sources for people with mental health difficulties. Mental illnesses can cause a variety of symptoms that may hinder the use of digital services. ${ }^{7}$ Therefore, it is paramount to identify the different roles of efficacy beliefs and the sources of obtained support and their effect on the intention to use services. The types of support related to the use of digital services provide new information on what should be developed and at what scale.

\section{Self-Efficacy}

Albert Bandura's ${ }^{13,19}$ socio-cognitive approach provides an established psychological model of human agency, which is explicated as individual or personal agency. Bandura argued that the most pervasive determinator of personal agency is selfefficacy, ie, people's beliefs in their capacity to produce desired results and forestall detrimental ones by their actions. Selfefficacy beliefs promoting optimism and self-enhancement play a pivotal role in the self-regulation of motivation through goals, challenges, and outcome expectations. There is evidence that self-efficacy beliefs can affect perceived usefulness and perceived ease of use of technology in general ${ }^{20}$ and especially health informatics applications. ${ }^{21}$

Furthermore, previous research suggests that an assessment of self-efficacy beliefs should correspond to the targeted performance and domain of interest. ${ }^{22}$ Thus, the construct of domain-specific self-efficacy should have stronger predictive power than the general self-efficacy scale. ${ }^{23}$ In health care contexts, for example, application-specific selfefficacy has been defined as an individual's judgment about their own ability to use health information portals (HIP) to acquire health information and services. ${ }^{24}$ It has been suggested that general self-efficacy would affect an individual's task-specific self-efficacy within the computer domain ${ }^{25}$ and even have a cumulative effect on software-specific selfefficacy. ${ }^{26}$ The suggested links between general self-efficacy and task-specific self-efficacy, however, have not been empirically established.

Previous studies show that Internet self-efficacy is positively related to Internet usage ${ }^{18}$ and that individuals' confidence in their own abilities to effectively master the new technology is important for adopting it. ${ }^{20}$ Applicationspecific self-efficacy also predicts consumer acceptance of health information portals. ${ }^{21,24}$ The technology acceptance model (TAM) is a widely used theory to explain an individual's behavioral intention to adopt a particular piece of technology. The model approaches the acceptance of technology by examining the individual's attitude from the viewpoints of perceived usefulness and perceived ease of use. ${ }^{27}$ Internet self-efficacy can be considered as an antecedent to perceived ease of use. There is evidence that health information technology (HIT) self-efficacy predicts behavioral intention to use digital services. ${ }^{28}$ 


\section{Proxy Efficacy}

Bandura $^{13}$ points out that personal agency is not sufficient to explain all forms of human agency because many things individuals seek can only be achieved through interdependent effort. He introduces the concept of proxy agency, in which

people try by one means or another to get those who have access to resources or expertise, or who wield influence and power to act at their behest to secure outcomes they desire. (p. 13) $)^{13}$

In some circumstances, individuals lack direct control over social conditions and institutional practices. Through proxy agency, individuals pursue well-being, security, and valued outcomes by trying to get those who have the expertise or influence and the power to act for them. ${ }^{13}$ For example, in the context of health care, patients' confidence in professionals' competence is termed proxy efficacy, which reflects an individual's confidence in the skills of a third party to act effectively on their behalf. ${ }^{29}$

Previous studies indicate that social support is also a fundamental part in adopting Internet use and new digital technologies. ${ }^{16,30}$ However social support has so far not been officially conceptualized as proxy agency. There is evidence that support from friends and family can encourage Internet adoption, the continuance of Internet use, ${ }^{31}$ and better Internet skills. ${ }^{32}$ Studies among older adults show that they rely on relatives and friends, rather than professionals, in seeking help and support for heterogeneous information and communications technology (ICT) needs. ${ }^{30,33}$ Social support from close people includes both informational and emotional support, ${ }^{17,34}$ provides possibilities for observational learning, and encourages the use of ICT technologies. ${ }^{16}$ Close people are favored over professional helpers, due to their in-depth knowledge of the novice user. ${ }^{30,33}$

Bandura $^{12}$ further states that proxy efficacy beliefs influence self-efficacy, and both types of efficacies have significant roles in behavioral change. Accordingly, stronger perceptions of behavioral self-efficacy and trust in health care providers' capabilities have been found to predict better adherence to health behavior change and promoting health. ${ }^{35,36}$ In particular, proxy agency has been intensively studied within cardiac rehabilitation settings. Studies have shown that proxy efficacy beliefs and self-efficacy on exercise intention are positively associated, ${ }^{37}$ and proxy efficacy beliefs depend heavily on the participant's experiences of the proxy agent. ${ }^{15,29}$ Furthermore, strong positive proxy efficacy beliefs, as well as self-efficacy beliefs, are evident when the proxy agent is supportive and engaging. Nonetheless, the amount of time spent with the proxy agent does not seem to correlate with proxy efficacy. ${ }^{15}$

In an ideal situation, proxy agency is a valuable vehicle or enabler to promote self-development. It helps individuals survive in diverse environments, find ways to overcome various physical or environmental limitations, and model behaviors to achieve their goals. However, proxy agency may carry some risks and causes for concern. Proxy control can serve as a means to avoid taking responsibility for one's actions and saving oneself from laborious tasks. An individual's personal competencies may not be developed, and there is vulnerability in relying on the competence, power, and favors of others. ${ }^{13}$ There is evidence that the convenience of proxy Internet use may inhibit the acquisition of Internet skills, ${ }^{38,39}$ and overreliance on proxy may also endanger the development of personal efficacy beliefs. ${ }^{14}$ Hänninen et al ${ }^{30}$ found that older adults' digital skills were varied, and some remain dependent on the continuous assistance of extended family members.

Prior studies have also established links between Internet skills and several demographic factors, including gender, age, and educational level. ${ }^{40-42}$ Thus, it is justified to analyze the effects of background factors, age, education level, and relationship status, along with self-efficacy, Internet self-efficacy, and proxy efficacy on the intention to use digital social and health care services.

\section{Aims of the Study}

The first aim of this study was to examine the relationship between proxy efficacy, general self-efficacy, Internet selfefficacy, and the use of digital social and healthcare services among adult mental health service users. The second aim is to gain further understanding of social support in using digital services among mental health service users. This study is warranted because previous research has not considered general self-efficacy, Internet self-efficacy, and proxy efficacy together as explanatory variables for the intention to use digital services. To serve the aforementioned aims, the study addresses the following research questions: 
RQ1Do proxy efficacy, general self-efficacy, and Internet self-efficacy predict the intention to use digital social and health care services among mental health service users?

RQ2Who do mental health service users reach out to for support using the digital social and health care services?

\section{Materials and Methods}

\section{Sample}

The study is part of the large project examining digital exclusion of socially marginalized groups, including people with vulnerabilities in mental health who formed a purposive sample in this study. Participants $(\mathrm{N}=121)$ for a cross-sectional survey were recruited between November 2020 and May 2020 through four organizations providing community-based mental health rehabilitation, support, and sheltered employment services for adults with mental health difficulties in southern Finland. The majority of participants (64\%) were recruited from a medium-sized public services provider, and the sample was complemented from three non-governmental organizations (NGOs) providing rehabilitation and peer support to their members. The calculated response rate for the enterprise was approximately $25 \%$. Participants from other organizations were individually invited to participate, and therefore their response rates remained unknown. Data collection was carried out with a questionnaire, and the participant had a choice to respond either in paper or digital form. Responses in paper form were returned anonymously in the provided envelopes.

The study was conducted according to the guidelines of the Finnish National Board on Research Integrity (2019), based on voluntary participation and informed consent. Ethical approval was obtained from the ethics committees for humanities at universities of Applied sciences in the Helsinki metropolitan area (Decision 6/2020; September 25, 2020). Mental health service users may experience cognitive problems; therefore, special effort was put into designing the questionnaire with a clear layout and simple language, and it was tested by several participants. NGO staff members were instructed to give advice on the questionnaire completion.

\section{Measures}

The questionnaire comprised several measures with 24 questions, most of which contained several items. Digital social and healthcare services referred to in this study are services such as online social welfare applications, remote appointments with professionals, use of the national patient data repository, use of health information portals, symptom assessments, peer support, and self-help programs offered mainly by governmental agencies, municipal authorities, and NGOs. In the questionnaire, examples of the most common digital social and health care services were provided to respondents.

This study focuses on 10 questions with 62 items. In addition, demographic questions including age, gender, level of education, and relationship status were explored. The respondents were asked about the use of social and health care services, use of the Internet, and the types of access methods and services they have at their disposal. Furthermore, respondents provided information on the support sources they used while accessing the Internet and digital services.

General self-efficacy was measured by 10 items on the Schwarzer and Jerusalem scale. ${ }^{43}$ In the scale, the possible responses are: (1) not at all true, (2) hardly true, (3) moderately true, and (4) exactly true. The Internet self-efficacy scale was adopted from the Eastin and LaRose ${ }^{18}$ study, with eight items measuring the use of Internet hardware and software at a general level. Proxy efficacy was operationalized through eight items on professional, family, friend, and volunteer efficacy, with the efficacy referring to respondents' confidence in the ability of the aforementioned persons to provide support in using digital services. ${ }^{14,15,29,37,44}$ The 5-point Likert scale, ranging from 1 ("totally disagree") to 5 ("totally agree"), was applied to both proxy efficacy and Internet self-efficacy response options. The behavioral intention to use digital social and health care services was used to indicate the use behavior. Following previous studies in health technology ${ }^{21,24,27}$ and the theory of planned behavior, ${ }^{45}$ a five-item measure for behavioral intention was planned. The first two items related to a person's overall readiness to use digital services and the likelihood of future use of digital services. Eagerness to apply for social welfare benefits or deal with health-related matters over the Internet was measured using two questions. The last item concerned preference between remote and face-to-face appointments with social and healthcare professionals. 


\section{Statistical Analysis}

Descriptive statistics and analyses were computed using IBM SPSS software (version 27, IBM Corp.). Descriptive statistics were conducted to describe demographic characteristics and background variables of the study sample, Internet access, the use of digital products and services, and the support received from various actors (see Tables 1 and 2). Average indices were calculated for the measures of self-efficacy, Internet self-efficacy, proxy efficacy, and intention to use digital health and social care services, and their internal consistency was estimated with Cronbach's alpha (see Table 3).

Pearson's product-moment correlation coefficient was applied to examine the correlations between the main variables and age (see Table 4). The background variables of gender, relationship status, and educational level were dichotomized.

Table I Demographic Characteristics, Internet Access, Services, and Usage Among the Study Participants

\begin{tabular}{|c|c|c|}
\hline \multirow{2}{*}{$\begin{array}{l}\text { Variable } \\
\text { Age (years), mean (SD), n = } 107\end{array}$} & \multicolumn{2}{|c|}{ Value } \\
\hline & 43.9 & $(12.6)$ \\
\hline \\
\hline Male & 45 & $(37.5)$ \\
\hline Female & 76 & $(62.5)$ \\
\hline \multicolumn{3}{|l|}{ Relationship status, $\mathbf{n}(\%)$} \\
\hline Married/in a relationship & 32 & $(26.4)$ \\
\hline Single/unmarried & 89 & $(73.6)$ \\
\hline \multicolumn{3}{|l|}{ Educational level, n (\%) } \\
\hline Secondary education & 86 & $(75.4)$ \\
\hline No secondary education & 28 & $(24.6)$ \\
\hline \multicolumn{3}{|l|}{ Internet usage, n (\%) } \\
\hline Every day or almost every day & 109 & $(90.1)$ \\
\hline Weekly, monthly, or several times a year & 9 & (7.4) \\
\hline Once a year or never & 3 & $(2.5)$ \\
\hline \multicolumn{3}{|l|}{ Places to access Internet, n (\%) } \\
\hline Home & 114 & (93.4) \\
\hline Family, friends, and neighbors & 71 & $(58.2)$ \\
\hline Public places & 63 & $(51.6)$ \\
\hline NGOs, parish & 32 & $(26.2)$ \\
\hline Social and health care services and institutions & 31 & (25.4) \\
\hline No access & I & $(0.8)$ \\
\hline \multicolumn{3}{|l|}{ Mobile and fixed Internet products, $n$ (\%) } \\
\hline Smartphone & 106 & $(86.9)$ \\
\hline Personal computer & 90 & $(73.8)$ \\
\hline Cable or NBN fixed broadband connection & 76 & $(62.3)$ \\
\hline Tablet computer & $4 I$ & $(33.6)$ \\
\hline Shared family computer & 17 & $(13.9)$ \\
\hline No Internet product & 3 & $(2.5)$ \\
\hline \multicolumn{3}{|l|}{ e-Identification methods, $n$ (\%) } \\
\hline Online bank IDs & 108 & $(88.5)$ \\
\hline Mobile IDs & 48 & $(39.3)$ \\
\hline None & 1 & $(0.8)$ \\
\hline \multicolumn{3}{|c|}{ Health and social services used within past year, $n$ (\%) } \\
\hline Social Insurance Institution services & 105 & $(86.1)$ \\
\hline Health care services & 96 & (78.7) \\
\hline Mental health services & 60 & $(49.2)$ \\
\hline Municipal social welfare services & 49 & $(40.2)$ \\
\hline Substance abuse services & 9 & (7.4) \\
\hline Family and social services & 7 & $(5.7)$ \\
\hline
\end{tabular}


Table 2 Assistance Received for Using Digital Services

\begin{tabular}{|l|c|c|}
\hline Variable & n & (\%) \\
\hline Family members & 70 & 57.9 \\
Friends, acquaintances, or relatives & 57 & 47.1 \\
No one - I solved the problem myself. & 45 & 37.2 \\
Social and health care professional & 20 & 16.5 \\
Digital support point in library & 11 & 9.1 \\
Organization (NGO)/ church employee or volunteer & 11 & 9.1 \\
I did not get any help, and I was not able to use the service. & II & 9.1 \\
City or municipal service point & 8 & 6.6 \\
\hline
\end{tabular}

Table 3 Construct Variables and Their Means, SDs, and Reliabilities

\begin{tabular}{|l|c|c|c|c|c|}
\hline Variable & Items & N & Mean & SD & Cronbach $\alpha$ \\
\hline Intention to use digital services & 5 & 119 & 3.20 & 1.03 & 0.83 \\
Proxy efficacy & 8 & 118 & 3.61 & 0.76 & 0.77 \\
Self-efficacy & 10 & 114 & 2.79 & 0.61 & 0.92 \\
Internet self-efficacy & 8 & 116 & 3.67 & 1.04 & 0.94 \\
\hline
\end{tabular}

Table 4 Correlations Among Main Variables

\begin{tabular}{|l|c|c|c|c|}
\hline Variable & & $\mathbf{I}$ & $\mathbf{2}$ & $\mathbf{3}$ \\
\hline I. Intention to use digital services & $\mathrm{r}$ & $-^{\mathrm{a}}$ & - & - \\
& $p$ value & - & - & - \\
2. Self-efficacy & $\mathrm{N}$ & - & - & - \\
& $\mathrm{r}$ & 0.05 & - & - \\
& $p$ value & 0.58 & - & - \\
3. Internet self-efficacy & $\mathrm{N}$ & 113 & - & - \\
& $\mathrm{r}$ & 0.54 & 0.28 & - \\
& $p$ value & $<0.001$ & 0.003 & - \\
4. Proxy efficacy & $\mathrm{N}$ & 115 & 111 & 0.28 \\
& $\mathrm{r}$ & 0.49 & 0.09 & 0.003 \\
& $p$ value & $<0.001$ & 0.33 & 114 \\
\hline
\end{tabular}

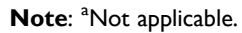

Subsequently, correlations between main and background variables were explored using the point-biserial correlation method. Linear regression models with the Enter method were then used to see whether self-efficacy, Internet selfefficacy, and proxy efficacy with background variables predict the intention to use digital social and health care services (see Table 5). Analyses were based on observations with no missing data (complete analyses). The validity of conditions was checked graphically with normality of residual distribution and linearity. Multicollinearity between the independent variables was explored using the VIF coefficients.

Moderation effects (age*self-efficacy, age*Internet self-efficacy) were preliminarily studied by regression analysis, but no significant effects were found. Mediation effects of Internet self-efficacy were further analyzed using Hayes' bootstrapping method. PROCESS macro 3.5.3 for SPSS was used for the mediation analysis, and 5000 bootstrap samples were used. The indirect effect was considered significant when the upper and lower bounds ( $95 \%$ confidence intervals) did not contain a value of zero. 
Table 5 Linear Regression Analysis (Dependent Variable: Intention to Use Digital Services)

\begin{tabular}{|c|c|c|c|c|c|c|}
\hline \multicolumn{7}{|c|}{ Model I ${ }^{\mathbf{a}}$} \\
\hline Independent Variable & $\beta$ & SE & Beta & $\mathbf{t}$ & $p$ value & VIF \\
\hline (constant) & -0.29 & 0.76 & & -0.38 & 0.71 & \\
\hline Self-efficacy & -0.14 & 0.14 & -0.09 & -0.96 & 0.34 & 1.09 \\
\hline Internet self-efficacy & 0.47 & 0.12 & 0.43 & 3.94 & $<0.001$ & 1.63 \\
\hline Proxy efficacy & 0.45 & 0.12 & 0.35 & 3.77 & $<0.001$ & 1.18 \\
\hline Age & 0.01 & 0.01 & 0.07 & 0.67 & 0.50 & 1.38 \\
\hline Gender ${ }^{\dagger}$ & 0.17 & 0.18 & 0.08 & 0.96 & 0.34 & 1.07 \\
\hline Relationship status $^{\dagger}$ & 0.12 & 0.20 & 0.05 & 0.60 & 0.55 & 1.05 \\
\hline Education $^{\dagger}$ & 0.23 & 0.21 & 0.09 & 1.07 & 0.29 & 1.07 \\
\hline \multicolumn{7}{|c|}{ Model $2^{b}$} \\
\hline Independent Variable & $\boldsymbol{\beta}$ & SE & Beta & $\mathbf{t}$ & $P$ value & VIF \\
\hline (constant) & 0.04 & 0.40 & & 0.10 & 0.92 & \\
\hline Internet self-efficacy & 0.40 & 0.08 & 0.40 & 5.02 & $<0.001$ & 1.10 \\
\hline Proxy efficacy & 0.48 & 0.10 & 0.37 & 4.72 & $<0.001$ & 1.10 \\
\hline
\end{tabular}

Notes: ${ }^{a} R^{2}=0.385$, Adjusted $R^{2}=0.334, F=7.6 ; p<0.001 ; N=93$.

${ }^{\mathrm{b}} \mathrm{R}^{2}=0.382$, Adjusted $\mathrm{R}^{2}=0.37 \mathrm{I}, \mathrm{F}=34.1 ; \mathrm{p}<0.00 \mathrm{I} ; \mathrm{N}=113$. ${ }^{\dagger}$ Dummy.

\section{Results}

\section{Respondents and Their Background}

Respondents were welcome to choose more than one option when responding to questions regarding their Internet use, access, services, and products, and recent use of digital social and health care services. Participants $(\mathrm{N}=121)$ had a mean age of 43.9 ( $\mathrm{SD}=10.4)$ years, over half were female $(62.5 \%)$, and most of them $(75.4 \%)$ had pursued secondary education. The vast majority had used social insurance services $(86.1 \%)$ and health care services (78.7\%) within the past year. Over $90 \%$ of participants used the Internet every day or almost every day, and for Internet access, $86.9 \%$ had a smartphone at their disposal. (See Table 1 for additional details on participants' background.)

The main source for support in using digital social and health care services were family (57.9\%) and friends (47.1\%) (see Table 2). Of the respondents, $16.5 \%$ had received help from social and health care professionals, $9.1 \%$ from a library or NGO, and $6.6 \%$ from municipal service points. However, on many occasions, respondents had solved the problems by themselves (37.2\%), and 9.1\% reported that they did not receive help from anyone, resulting in a failure to use the service.

\section{Scale Internal Consistencies}

The internal consistencies of intention to use digital services, general self-efficacy, proxy efficacy, and Internet selfefficacy scales were assessed by calculating Cronbach's alpha (Table 3). This analysis indicated that the intention to use digital services, general self-efficacy, and Internet self-efficacy measures had adequate internal consistency with alpha scores of $0.83,0.92$, and 0.94 , respectively. The proxy efficacy demonstrated acceptable properties with an internal consistency of Cronbach's $\alpha=0.77$.

\section{Intention to Use Digital Social and Health Care Services}

When participants were asked if they would use digital social and health services in the future, the vast majority (68.8\%) of respondents partially or totally agree. Primarily accessing social and health care services through digital channels was preferred by slightly over half of the respondents $(56.5 \%)$. When needing to talk to social and health care professionals, only $22.9 \%$ of the respondents would partially or totally agree on choosing a remote appointment over a face-to-face meeting (Table 6). 
Table 6 The Distributions of Responses Regarding Behavioral Intentions

\begin{tabular}{|c|c|c|c|c|c|c|}
\hline Statements & $\mathbf{N}$ & $\begin{array}{l}\text { I Totally } \\
\text { Disagree } \\
\text { (\%) }\end{array}$ & $\begin{array}{l}\text { I Partially } \\
\text { Disagree } \\
\text { (\%) }\end{array}$ & $\begin{array}{l}\text { I Neither } \\
\text { Agree nor } \\
\text { Disagree } \\
\text { (\%) }\end{array}$ & $\begin{array}{l}\text { I Partially } \\
\text { Agree (\%) }\end{array}$ & $\begin{array}{l}\text { I Totally } \\
\text { Agree } \\
\text { (\%) }\end{array}$ \\
\hline $\begin{array}{l}\text { I will use digital social and health services whenever } \\
\text { possible in the future. }\end{array}$ & 121 & 8.2 & 9 & 13.1 & 33.6 & 35.2 \\
\hline $\begin{array}{l}\text { I am likely to primarily deal with social and health } \\
\text { services in electronic form in the future. }\end{array}$ & 120 & 11.5 & 9 & 21.3 & 30.3 & 26.2 \\
\hline $\begin{array}{l}\text { I want to manage matters related to my social welfare } \\
\text { benefits via the Internet in the future. }\end{array}$ & 121 & 13.1 & 5.7 & 17.2 & 27 & 36.1 \\
\hline $\begin{array}{l}\text { I would like to primarily take care of my health-related } \\
\text { issues via the Internet in the future. }\end{array}$ & 121 & 27 & 15.6 & 22.1 & 23.8 & 10.7 \\
\hline $\begin{array}{l}\text { When I need to talk to a professional (social worker, } \\
\text { doctor, nurse, etc.) in the future, if possible, I will prefer } \\
\text { to meet remotely rather than face-to-face. }\end{array}$ & 120 & 41.8 & 18 & 15.6 & 13.1 & 9.8 \\
\hline
\end{tabular}

\section{Correlations}

The correlations between main variables and age were examined using Pearson's correlation coefficient. The intention to use digital social and health care services correlated significantly with proxy efficacy, $r(115)=0.49 ; p<0.001$, and Internet self-efficacy, $r(117)=0.49 ; p<0.001$. Self-efficacy did not correlate significantly with the intention to use digital services. However, self-efficacy and Internet self-efficacy correlated significantly with each other $r(111)=0.28$; $p=0.003$. Significant correlation was also found between proxy efficacy and Internet self-efficacy, $r(114)=0.28 ; p=$ 0.003 (Table 4). Age was negatively correlated with the intention to use services and Internet self-efficacy. Younger adults were more confident in their Internet skills, $r(103)=-0.50 ; p<0.001$, and more inclined to use digital services, $r$ $(106)=-0.25 ; p=0.01$. Compared to women, men feel more confident in their Internet skills, $r(116)=-0.25 ; p=0.007$. Furthermore, being in a relationship was positively related to Internet skills, $r(116)=0.19 ; p=0.04$. A higher educational level was positively related to Internet self-efficacy, $r(109)=0.28 ; p=0.004$ and the intention to use digital services, $r$ $(112)=0.23 ; p=0.01$.

\section{Linear Regression Analysis}

Factors that explain the intention to use digital social and health care services were examined with linear regression analysis. Independent variables in the analysis were self-efficacy, proxy efficacy, and Internet self-efficacy. Relevant background variables such as age, gender, relationship status, and level of education were included in the analysis. The VIF coefficients ranged from 1.05 to 1.63 , showing no excessive multicollinearity in the regression analysis. The first regression model (see Table 5) includes all the independent variables examined. None of the demographics were significant and were therefore not included in the second model. Both models explain perceived control quite well $\left(R^{2}\right.$ $=0.385 / 0.382$ ). The analyses show that both Internet self-efficacy and proxy efficacy explain the intention to use digital social and health care services.

According to regression analysis (Table 5), the effect of self-efficacy was not significant, and self-efficacy did not moderate the effect of other independent variables. Mediation analysis using the bootstrap method revealed that selfefficacy has an indirect positive effect on the intention to use digital services, and Internet self-efficacy was the mediating variable (coefficient $0.22 ; 95 \%$ CI $0.08-0.39 ; p=0.002$ ).

\section{Discussion}

The first aim of this cross-sectional study was to explore the relationship between proxy efficacy, general selfefficacy, Internet self-efficacy, and the use of digital social and healthcare services among adult mental health service users within four Finnish NGOs. The second aim was to find out sources of social support for using digital services. 
To understand the characteristics of the purposive sample, several background variables were examined. Of the respondents, 76 were women and 45 were men, the average age was 43.9 years, and $75.4 \%$ had secondary education. Over $90 \%$ of the participants used the Internet every day or almost every day, mostly at home. The majority of respondents had a smartphone and personal computer at their disposal and possessed online bank IDs required for using digital services in Finland. To summarize, respondents were well-equipped with ICT, reflecting the current situation in Finland, where $91 \%$ of adults use a smartphone and $80 \%$ a personal computer daily. ${ }^{46}$ Respondents also reported relatively high proxy efficacy and Internet self-efficacy beliefs, and accordingly, over one-third of them reported that they had been able to solve problems encountered using digital services by themselves. A cautious conclusion can be drawn that a lack of digital devices or general ICT skills does not pose a serious risk of digital exclusion among respondents despite their vulnerable backgrounds, $\mathrm{cf}^{3}{ }^{3}$ Thus, the contributions of this study lie in adding understanding to the role of self-efficacy, Internet self-efficacy, and proxy efficacy in explaining the use of digital services.

According to the findings, respondents' willingness to use digital services was significantly affected by their Internet efficacy and proxy efficacy beliefs. General self-efficacy beliefs were not directly related to the intention to use the services, supporting previous claims that self-efficacy should be assessed by the targeted performance, ${ }^{22}$ and domainspecific self-efficacy holds better predictive power than general self-efficacy. ${ }^{23}$ However, previous studies ${ }^{25,26}$ suggest that self-efficacy has an indirect positive effect on intention. The mediation analysis results confirmed that self-efficacy beliefs enhanced Internet self-efficacy. Overall, the present findings are consistent with the previous findings that Internet self-efficacy as task-specific efficacy enhances the use of health-related digital services. ${ }^{21,24}$ The assumption ${ }^{12,29}$ that proxy efficacy beliefs and self-efficacy beliefs reinforce each other was not supported. These findings suggest that to enhance service users' confidence in using digital services, reliance on Internet self-efficacy and proxy efficacy, rather than general self-efficacy beliefs, should be encouraged.

In accordance with previous studies, proxy efficacy beliefs ${ }^{17}$ and social support ${ }^{16,30}$ predicted the intention to use digital services. The respondents received assistance mostly from close family members, relatives, and friends, whereas assistance from official actors remained at a low level. Strikingly, social and health care professionals provided support to only $16.5 \%$ of respondents, while the recent Act on the Provision of Digital Services (2019) ${ }^{47}$ obligates public authorities to provide support for service users. Furthermore, the findings show that the third sector (ie, volunteers, NGOs, and parishes) had only a supplementary role in digital support for mental health service users as a vulnerable group, in contrast with the assumptions within the operating model for digital support in Finland. ${ }^{48}$ Instead, the findings emphasize the role of "warm experts", ie, family members and other close ones, in giving support, consistent with previous studies. ${ }^{16,30,34,40,49}$

According to Bakardjieva, ${ }^{16}$ warm experts are unique for their in-depth knowledge of the needs of novice users and are thus able to give appropriate instructional and emotional support to them. For example, when older adults have potential support close at hand, such as a partner who uses technology, they are more likely to be Internet users. ${ }^{50}$ The quality of proxy agents is an important factor for engaging individuals with new behaviors. ${ }^{14,15}$ On the other hand, support by warm experts can compensate for deficiencies in individuals' competence and self-efficacy; but on the other, there may also be a risk of over-reliance on others with regard to digital matters. ${ }^{14,38,39}$ Proxy agents need to find ways to foster proxy efficacy while simultaneously developing self-reliance.

Overall, participants in this study were willing to use digital social and health care services in the future. Two-thirds of the respondents would use digital services whenever possible and over half would primarily take care of their social and health care affairs via the Internet. This is consistent with previous findings that mental health service users benefit from digital services, and they are generally inclined to use them. ${ }^{3,4,51}$ However, regarding the mode of service, most respondents $(59.8 \%)$ did prefer face-to-face appointments when they need to talk to professionals. Similarly, vulnerable young people with more advanced digital skills prefer face-to-face discussions with professionals when talking about difficult personal issues. ${ }^{52}$ When dealing with complex issues, digital welfare services seem to supplement rather than substitute face-to-face appointments. ${ }^{10,53}$ A preference for face-to-face interactions is also documented among prisoners. ${ }^{54}$ Moreover, mental health illnesses may induce symptoms that affect cognitive skills and make it difficult to achieve a therapeutic relationship with professionals via remote appointments. ${ }^{3,4}$ People with mental health problems 
may have concerns about using web-based services and would rather choose appointments with the professionals in person. ${ }^{55}$

Taken together, these findings suggest that while online contacts might be appropriate for running regular businesses, online contacts cannot replace face-to-face contacts when issues are difficult and complicated, such as welfare applications with multiple required attachments or which involve deeply personal matters, such as life crises.

The digital transformation is a constant state where technological advances are rapidly emerging. Therefore, vulnerable groups need continuous support to prevent their digital exclusion. Proxy agents may increase motivation to use the web-based services. This study points out that close people are key supporters, and therefore, more attention should be paid to the quality of proxy support and its role alongside other forms of support. ${ }^{49,56}$ Further research on efficacy beliefs is crucial. Exploring whether informal support sources benefit self-efficacy, and whether informal and formal support differs in terms of the effect on self-efficacy, may offer guidance in determining what kind of support could be most useful. The quality dimensions of proxy agency, especially within the mental health context, would also benefit from closer scrutiny as support needs vary.

\section{Limitations}

The study has been carried out in four organizations providing community-based mental health services that mainly operate in southern Finland. The COVID-19 pandemic substantially hindered data collection when researchers' face-toface contacts with service users were restricted, thus making it harder to reach target groups and subsequently affecting the sample diversity. It is plausible that service users with digital devices and more advanced digital skills were more motivated to participate in the study when instructed by staff members. However, the questionnaire was offered in paper and electronic format, which provided the opportunity to participate even without Internet access. It is also worth pointing out that only $49 \%$ of respondents reported having used mental health services within the past year, even though at the same time, they were users of various community-based mental health services, indicating that participants' mental health problems were also varied. The sample represented individuals who participated in rehabilitative services within a community setting and various peer group activities. Overall, the group of respondents seemed to possess the adequate functional capacity to use digital devices and services. Hence, it is reasonable to assume that the survey did not reach the individuals with the most debilitating constellation of symptoms that potentially prevents the use of digital services. The survey, which was in Finnish, also excluded potential non-Finnish speaking participants, even though some of them did fill in the questionnaire with staff members' support. Some degree of bias is also evident because the most underprivileged individuals in need of services are beyond reach, meaning they are unable to provide valuable information on their challenges in a digital environment.

Together with the small sample size, the aforementioned biases restrict the generalizability of the results to a wider number of mental health service users. Moreover, it was found that Internet self-efficacy and proxy efficacy predicted the intention to use digital health care and social welfare services, but due to the cross-sectional data, causal relationships cannot be confirmed. In the future, the effects of proxy efficacy on digital skills need to be examined using a longitudinal design.

\section{Conclusion}

Mental health service users constitute a group of people who are at greater risk of digital exclusion. Internet self-efficacy and proxy efficacy are major contributors to the intention to use digital social and health care services. The need for support from family, friends, volunteers, and professionals is particularly obvious. The support received from "warm experts" (ie, family and friends) was significantly higher than the support from other sources. Proxy agents may serve as facilitators to reduce the digital divide and promote the use of digital services by complementing individuals' selfefficacy and Internet self-efficacy beliefs. However, proxy agents should be aware of the over-reliance factor and foster individuals' self-reliance throughout the process. Peer and formal support should be addressed to enhance the quality of proxy efficacy. It is important to focus on the supply and quality of sources of support to ensure adequate coverage and tailored support for individual needs. Overall, proxy agents would benefit from structural education on guidance practices to develop digital support towards a uniform level of quality. 


\section{Abbreviations}

ICT, Information and communications technology; NGO, Non-governmental organization.

\section{Funding}

This research was conducted as part of the "Toward a Socially Inclusive Digital Society: Transforming Service Culture" project (DigiIN) and was funded by the Strategic Research Council at the Academy of Finland [grant numbers 327169 and 327145].

\section{Disclosure}

Dr Soile Juujärvi reports personal fees from Edistia Group outside the submitted work. She is also a member of the advisory board of one of the organizations involved in the study. However, the study has not been on its agenda. The authors report no other conflicts of interest in this work.

\section{References}

1. Helsper EJ. Digital inclusion: an analysis of social disadvantage and the information society; 2008. London, UK: Department for Communities and Local Government. Available from: http://eprints.lse.ac.uk/id/eprint/26938. Accessed June 15, 2021.

2. Heponiemi T, Jormanainen V, Leemann L, Manderbacka K, Aalto A, Hyppönen H. Digital divide in perceived benefits of online health care and social welfare services: national cross-sectional survey study. $J$ Med Internet Res. 2020;22(7):e17616. doi:10.2196/17616

3. Berry N, Lobban F, Bucci S. A qualitative exploration of service user views about using digital health interventions for self-management in severe mental health problems. BMC Psychiatry. 2019;19:35. doi:10.1186/s12888-018-1979-1

4. Liberati E, Richards N, Parker J, et al. Remote care for mental health: qualitative study with service users, carers and staff during the COVID-19 pandemic. BMJ Open. 2021;11:e049210. doi:10.1136/bmjopen-2021-049210

5. Andersson G, Cuijpers P, Carlbring P, Riper H, Hedman E. Guided internet-based vs face-to-face cognitive behavior therapy for psychiatric and somatic disorders: a systematic review and meta-analysis. World J Psychiatry. 2014;13(3):288-295. doi:10.1002/wps.20151

6. Borghouts J, Eikey E, Mark G, et al. Barriers to and facilitators of user engagement with digital mental health interventions: systematic review. $J$ Med Internet Res. 2021;23(3):e24387. doi:10.2196/24387

7. Greer B, Robotham D, Simblett S, Curtis H, Griffiths H, Wykes T. Digital exclusion among mental health service users: qualitative investigation. $J$ Med Internet Res. 2019;21(1):e11696. doi:10.2196/11696

8. Thomas J, Barraket J, Wilson CK, et al. Measuring Australia's digital divide: The Australian digital inclusion index 2020. RMIT University. Centre for Social Impact. Telstra.2020. doi:10.25916/5f6eb9949c832

9. Too L, Leach L, Butterworth P. Mental health problems and internet access: results from an Australian national household survey. JMIR Ment Health. 2020;7(5):e14825. doi:10.2196/14825

10. Kaihlanen A, Virtanen L, Valkonen P, et al. Haavoittuvat ryhmät etäpalveluiden käyttäjinä [Vulnerable groups as remote service users]. Finnish institute for health and welfare. Tutkimuksesta tiiviisti 33/2021. Available from: http://urn.fi/URN:ISBN:978-952-343-687-9. Accessed July 19, 2021. Finnish.

11. Stafford E, Brister T, Duckworth K, Rauseo-Ricupero N, Lagan S. Needs and experiences of users of digital navigation tools for mental health treatment and supportive services: survey study. JMIR Ment Health. 2021;8(6):e27022. doi:10.2196/27022

12. Bandura A. Self-Efficacy: The Exercise of Control. New York, NY: Freeman; 1997. ISBN: 0-7167-2626-2.

13. Bandura A. Social cognitive theory: an agentic perspective. Annu Rev Psychol. 2001;52:1-26. doi:10.1146/annurev.psych.52.1.1

14. Bray SR, Brawley L, Millen J. Relationship of proxy efficacy and reliance to home-based physical activity after cardiac rehabilitation. Rehabil Psychol. 2006;51:224-231. doi:10.1037/0090-5550.51.3.224

15. Bray SR, Saville P, Brawley L. Determinants of clients' efficacy in their interventionists and effects on self-perceptions for exercise in cardiac rehabilitation. Rehabil Psychol. 2013;58:185-195. doi:10.1037/a0032169

16. Bakardjieva M. Internet Society: The Internet in Everyday Life. London: SAGE Publications; 2005. ISBN: 978076194338.

17. Chuenphitthayavut K, Zihuang T, Zhu T. The prediction of behavioral intention to use online mental health interventions. Psych J. $2020 ; 9: 370-382$. doi:10.1002/pchj.333

18. Eastin MS, LaRose R. Internet self-efficacy and the psychology of the digital divide. J Comput Mediat Commun. 2000;6. doi:10.1111/j.10836101.2000.tb00110.x

19. Bandura A. Toward a psychology of human agency. Perspect Psychol Sci. 2006;1(2):164-180. doi:10.1111/j.1745-6916.2006.00011.x

20. Kulviwat S, Bruner GC, Neelankavil JP. Self-efficacy as an antecedent of cognition and affect in technology acceptance. J Consum Market. 2014;31:190-199. doi:10.1108/JCM-10-2013-0727

21. Kim NE, Han SS, Yoo KH, Yun KE. The impact of user's perceived ability on online health information acceptance. Telemed J E Health. 2012;18 (9):703-708. doi:10.1089/tmj.2011.0277

22. Hsu MH, Chiu CM. Internet self-efficacy and electronic service acceptance. Decis Support Syst. 2004;38:369-381. doi:10.1016/j.dss.2003.08.001

23. Compeau D, Higgins CA, Huff S. Social cognitive theory and individual reactions to computing technology: a longitudinal study. MIS Quarterly. 1999;23:145-158. doi:10.2307/249749

24. Tao D, Shao F, Wang H, Yan M, Qu X. Integrating usability and social cognitive theories with the technology acceptance model to understand young users' acceptance of a health information portal. Health Informatics $J$. 2020;26:1347-1362. doi:10.1177/1460458219879337

25. Marakas MG, Yi MY, Johnson RD. The multilevel and multifaceted character of computer self-efficacy: toward clarification of the construct and an integrative framework for research. Inf Syst Res. 1998;9(2):126-163. doi:10.1287/isre.9.2.126 
26. Agarwal R, Sambamurthy V, Stair RM. Research report: the evolving relationship between general and specific computer self-efficacy - an empirical assessment. Inf Syst Res. 2000;11(4):418-430. doi:10.1287/isre.11.4.418.11876

27. Holden RJ, Karsh BT. The technology acceptance model: its past and its future in health care. J Biomed Inform. 2010;43:159-172. doi:10.1016/j. jbi.2009.07.002

28. Kim J, Park H. Development of a health information technology acceptance model using consumers' health behavior intention. J Med Internet Res. 2012;14(5):e133. doi:10.2196/jmir.2143

29. Bray SR, Gyurcsik N, Culos-Reed S, Dawson K, Martin K. An exploratory investigation of the relationship between proxy efficacy, self-efficacy and exercise attendance. J Health Psychol. 2001;6:425-434. doi:10.1177/135910530100600405

30. Hänninen R, Taipale S, Luostari R. Exploring heterogeneous ICT use among older adults: the warm experts' perspective. New Media Soc. 2021;23 (6):1584-1601. doi:10.1177/1461444820917353

31. Hsieh JP, Arun RA, Keil M. Addressing digital inequality for the socioeconomically disadvantaged through government initiatives: forms of capital that affect ICT utilization. Inf Syst Res. 2011;22(2):233-253. doi:10.1287/isre.1090.0256

32. van Deursen A, van Dijk J. Internet skills and the digital divide. New Media Soc. 2011;13(6):893-911. doi:10.1177/1461444810386774

33. Hunsaker A, Nguyen MH, Fuchs J, Djukaric T, Hugentobler L, Hargittai E. He explained it to me and I also did it myself”: how older adults get support with their technology uses. Socius. 2019;5:237802311988786. doi:10.1177/2378023119887866

34. Chu RJC. How family support and internet self-efficacy influence the effects of e-learning among higher aged adults - analyses of gender and age differences. Comput Educ. 2010;55(1):255-264. doi:10.1016/j.compedu.2010.01.011

35. Christensen AJ, Wiebe JS, Benotsch EG, Lawton WJ. Perceived health competence, health locus of control, and patient adherence in renal dialysis. Cognit Ther Res. 1996;20(4):411-421. doi:10.1007/BF02228042

36. Birkhäuer J, Gaab J, Kossowsky J, et al. Trust in the health care professional and health outcome: a meta-analysis. PLoS One. 2017;12(2): e0170988. doi:10.1371/journal.pone.0170988

37. Bray SR, Cowan H. Proxy efficacy: implications for self-efficacy and exercise intentions in cardiac rehabilitation. Rehab Psychol. 2004;49 (1):71-75. doi:10.1037/0090-5550.49.1.71

38. Selwyn N. Digital division or digital decision? A study of non-users and low-users of computers. Poetics. 2006;34:273-292. doi:10.1016/j. poetic.2006.05.003

39. Reisdorf BC, Groselj D. Internet (non-)use types and motivational access: implications for digital inequalities research. New Media Soc. 2017;19 (8):1157-1176. doi:10.1177/1461444815621539

40. Courtois C, Verdegem P. With a little help from my friends: an analysis of the role of social support in digital inequalities. New Media Soc. 2016;18:508-1527. doi:10.1177/1461444814562162

41. Tobitt S, Percival R. Switched on or switched off? A survey of mobile, computer and Internet use in a community mental health rehabilitation sample. J Ment Health. 2019;28(1):4-10. doi:10.1080/09638237.2017.1340623

42. Zhao Y, Ni Q, Zhou R. What factors influence the mobile health service adoption? A meta-analysis and the moderating role of age. Int $J$ Inf Manage. 2018;43:342-350. doi:10.1016/j.ijinfomgt.2017.08.006

43. Schwarzer R, Jerusalem M. Generalized self-efficacy scale. In: Weinman J, Wright S, Johnston M, editors. Measures in Health Psychology: A User's Portfolio Causal and Control Beliefs. Windsor, UK: NFER-NELSON; 1995:35-37. ISBN: 0708707335.

44. Bray SR, Gyurcsik N, Ginis K, Culos-Reed S. The proxy efficacy exercise questionnaire: development of an instrument to assess female exercisers' proxy efficacy beliefs in structured group exercise classes. J Sport Exerc Psychol. 2004;26:442-456. doi:10.1123/jsep.26.3.442

45. Ajzen I. The theory of planned behavior. Organ Behav Hum Decis Process. 1991;50:179-211. doi:10.1016/0749-5978(91)90020-T

46. Ministry of Finance. Digitaitokartoitus - digitaalinen kysely [Survey of digital skills]; 2020. Available from: https://vm.fi/documents/10623/ 30029448/Digitaitokartoitus+\%E2\%80\%93+Digitaalinen+kysely.pdf/52d627ca-89a0-605d-5003a0eff0248898/Digitaitokartoitus+\%E2\%80\%93 + Digitaalinen+kysely.pdf?t=1598850515996. Accessed July 5, 2021. Finnish.

47. Laki digitaalisten palvelujen tarjoamisesta [act on the provision of digital services]; 2019. Available from: https://www.finlex.fi/fi/laki/alkup/2019/ 20190306. Accessed June 24, 2021. Finnish.

48. Ministry of Finance. Digituen toimintamalliehdotus [Policy proposal for support in digital skills]. AUTA -hankkeen projektiryhmän loppuraportti; 2017. Available from: https://vm.fi/documents/10623/6581896/AUTA+raportti.pdf/74d0c25e-fa60-43c6-8856-c418faef9085. Accessed July 5, 2021. Finnish.

49. Helsper EJ, van Deursen AJ. Do the rich get digitally richer? Quantity and quality of support for digital engagement. Inf Commun Soc. 2017;20:700-714. doi:10.1080/1369118X.2016.1203454

50. König R, Seifert A, Doh M. Internet use among older Europeans: an analysis based on SHARE data. Univ Access Inf Soc. 2018;17:621-633. doi:10.1007/s10209-018-0609-5

51. Robotham D, Satkunanathan S, Doughty L, Wykes T. Do we still have a digital divide in mental health? A five-year survey follow-up. $J$ Med Internet Res. 2016;18(11):e309. doi:10.2196/jmir.6511

52. Granholm C. Blended lives: ICT talk among vulnerable young people in Finland. YOUNG. 2016;24(2):85-101. doi:10.1177/1103308815613188

53. Hansen HT, Lundberg K, Syltevik LJ. Digitalization, street-level bureaucracy, and welfare users' experiences. Soc Policy Adm. 2018;52(1):67-90. doi: $10.1111 /$ spol.12283

54. Järveläinen E, Rantanen T. Incarcerated people's challenges for digital inclusion in Finnish prisons. Nord J Criminol. 2020. doi:10.1080/ 2578983X.2020.1819092

55. Rantanen T, Gluschkoff K, Silvennoinen P, Heponiemi T. The associations between mental health problems and attitudes toward web-based health and social care services: evidence from a Finnish population-based study. J Med Internet Res. 2021;23(9):e28066. doi:10.2196/28066

56. Dolničar V, Grošelj D, Filipovič Hrast M, Vehovar V, Petrovčič A. The role of social support networks in proxy internet use from the intergenerational solidarity perspective. Telemat Inform. 2018;35(2):305-317. doi:10.1016/j.tele.2017.12.005 


\section{Publish your work in this journal}

Psychology Research and Behavior Management is an international, peer-reviewed, open access journal focusing on the science of psychology and its application in behavior management to develop improved outcomes in the clinical, educational, sports and business arenas. Specific topics covered in the journal include: Neuroscience, memory and decision making; Behavior modification and management; Clinical applications; Business and sports performance management; Social and developmental studies; Animal studies. The manuscript management system is completely online and includes a very quick and fair peer-review system, which is all easy to use. Visit http://www.dovepress.com/testimonials.php to read real quotes from published authors.

Submit your manuscript here: https://www.dovepress.com/psychology-research-and-behavior-management-journal 